\title{
Pattern of Limb Amputations in Male Patients in a Nigerian Teaching Hospital.
}

\author{
Odatuwa-Omagbemi D. O. \\ Bmed. Sc., Mbbs, Fmcs. \\ Department Of Surgery, Delta State University, Abraka, Nigeria.
}

\begin{abstract}
:
Introduction: Most amputation surgeries worldwide are carried out in male patients. This negatively affects the socio-economic fortunes of the individual, family and society especially in places were rehabilitative and prosthetic facilities are lacking.

The aim of this study is to highlight the pattern of limb amputation surgeries in male patients in our centre with a view to suggesting possible ways of prevention and improvement in the functionality and quality of life of amputees.

Patients and Methods: Case notes of male patients who had amputation surgeries during the study period in the centre were retrieved from the records department and relevant information extracted. The extracted data were analysed accordingly.

Results: Sixty three male patients had 69 limb amputation surgeries in the centre during the study period. The mean age of the patients was $48.7 \pm 20.6$ years. The most frequent level of amputation was at below knee level in $46 \%$ of cases followed by above knee in $17.4 \%$ of cases. The lower limb was involved in $74.5 \%$ of cases, the rest $25.5 \%$ involving the upper limb. Diabetic foot disease was the commonest indication for amputation in $37.7 \%$ of cases followed by trauma in $30.4 \%$ of cases. Wound infection was the most frequent post-operative complication occurring in $43.5 \%$ of wounds in this study.

Conclusion: Limb amputation surgeries frequently involve male patients with diabetic foot disease and trauma ranking as the most common indications here. Preventive measures such education of diabetic patients on foot car and, public enlightenment on accident and trauma prevention strategies will go a long way in reducing the burden of amputation. Making prosthesis available and affordable to amputees is also suggested as a way of improving on the quality of life and functionality of amputees.
\end{abstract}

\section{Introduction}

Limb amputation surgeries have been carried out from time immemorial. Amputation is one of the commonest procedures in Orthopaedic practice in Nigeria. ${ }^{1,2 .}$

Major limb amputation represents a serious disability compounded in developing countries by difficulty in obtaining prosthesis and the paucity of efficient rehabilitative facilities in our hospitals. The effect is more far reaching if the amputation affects the usual male bread winner of the family and in Africa, the extended family. ${ }^{3,4}$.

Amputation is often viewed as a failure of treatment if the decision to do it is not taken as soon as patient presents. However, in many cases amputation of the limb is the most viable option of treatment for the patients' condition in order to save his life or improve on his quality of life. ${ }^{1}$.

Several studies have shown that the male sex is the most frequently involved in amputations the male sexbeing a prominent risk factor for limb amputation. ${ }^{1,2,3,4,5,6,7,8,9,10}$. The man is the primary bread winner in many families, thus amputations in them has a marked negative psychological and socio economic impact especially in resource poor societies like ours.

The aim of this study is to X-ray the pattern and indications for extremity amputations among male patients at the Delta State University Teaching Hospital, Oghara in Nigeria and to make suggestions on possible preventive measures and also proper rehabilitation in terms of prosthetic acquisition and other measures for those who must have the surgery.

\section{Patients And Methods}

This was a retrospective study of male patientswho underwent limb amputation surgeries at the Delta State University Teaching Hospital, Oghara, Delta State, Nigeria between January, 2011 and June, 2013. Case notes of all the male patients who had limb amputations during the period were retrieved from the medical records department after checking through theatre and ward records to collate the list of amputees. Information on patients' age, indication and levels of amputation, limb involvement and laterality, post-operative complications and other relevant data were extracted and entered into a previously prepared proforma for that 
purpose. Patients whose records were not complete or whose case notes were missing were excluded from this study.

Data were analysed using the Statistical Package for Social Sciences (SPSS) version 17 for calculation of means, percentages, standard deviations and drawing of charts.

\section{Results}

Eighty six patients had amputation surgeries in the hospital during the study period out of which, 63 were males and 23 were females giving a male to female ratio of 2.7:1.

The ages of the male patients ranged from $15-86$ years with a mean of $48.7 \pm 20.6$ years. Figure 1.shows the age distribution of the male patients. The age groups; $15-24$ and $45-54$ had the highest number of patients making up $20.6 \%$ and $22.2 \%$ respectively.

A total of 69 amputation surgeries were carried out on the 63 male patients in this study. The most frequent level of amputation was at below knee level which made up $46 \%$ of all the amputation surgeries in males. Above knee amputation was the second most frequent $(17.4 \%)$ followed by above elbow amputation in $13 \%$ of the cases. Table 1.

Major amputations involving the upper and lower limbs made up 78.3\% of cases, the rest being minor amputations involving the toes and the fingers. The lower limbs were affected in $74.5 \%$ of cases and upper limbs in $25.5 \%$ of cases. Three of the patients had initial below knee amputations reviewed to above knee level due to flap necrosis and ascending gangrene and infection, one had bilateral below knee amputations at various times for diabetic foot disease while still another patient had an above knee amputation on the left and one year later, a below knee amputation on the right due to peripherial vascular disease. Another patient had two fingers amputated at various times as a result of post-traumatic gangrene.

Diabetic foot disease was the commonest indication for amputation in this study accounting for $37.7 \%$ of cases (26 patients) followed by trauma in 21 patients $(30.4 \%)$ and peripherial vascular disease in 10 patients $(14.5 \%)$. See table 2.for further details.

Of the 69 amputation surgeries in male patients, close to half of the wounds (47.8\%) healed primarily without complications. The remaining 52.2\% developed one complication or the other ranging from postoperative wound infection in $43.5 \%$ of cases, wound break down requiring secondary suturing in 3 cases $(4.3 \%)$ to death in 4 cases ( $6.3 \%$ mortality). Table 3 .

The average length of hospital stay of male amputees was $37.1^{+} 25.7$ days. The longest staying patient stayed for 110 days. He had other complications of diabetes mellitus, septicaemia and wound complications. The shortest staying male amputee was a case of finger amputation for post-traumatic gangrene, a day case that stayed for a few hours.
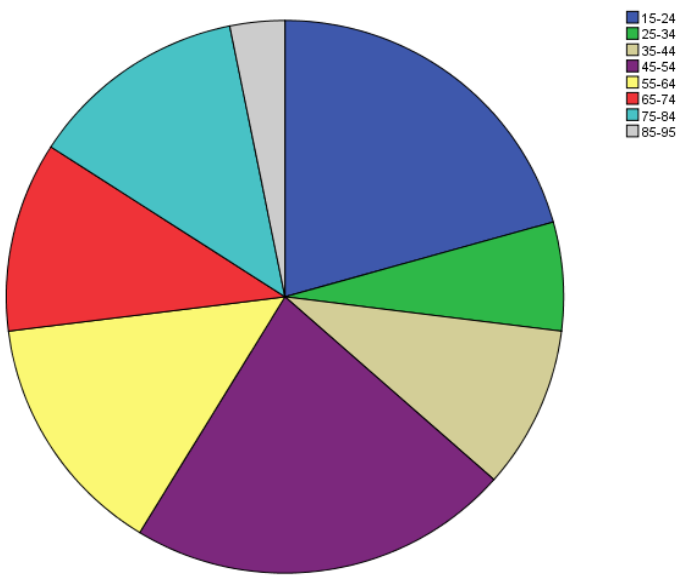

Fig.1, Age Distribution Of Patients In Years.

Table 1.Levels Of Amputation In Male Patients

\begin{tabular}{|l|l|l|}
\hline LEVEL OF AMPUTATION & NO. OF PATIENTS & PERCENTAGE \\
\hline BELOW KNEE & 32 & 46.4 \\
ABOVE KNEE & 12 & 17.8 \\
FINGERS & 9 & 13.0 \\
ABOVE ELBOW & 8 & 11.6 \\
TOES & 6 & 8.7 \\
BELOW ELBOW & 2 & 2.9 \\
\hline
\end{tabular}


Pattern of Limb Amputations in Male Patients in a Nigerian Teaching Hospital.

Table 2.Indications for Amputations In Male Patients.

\begin{tabular}{|l|l|l|}
\hline INDICATION & NO. OF PATIENTS & PERCENTAGE \\
\hline DIABETIC FOOT DISEASE & 26 & 37.68 \\
TRAUMA & 21 & 30.40 \\
PERIPHERIAL VASCULAR DISEASE & 10 & 14.50 \\
COMPLICATION OF TBS TREATMENT & & \\
OF LIMB INJURIES & 5 & 7.24 \\
MALIGNANCIES & 3 & 4.3 \\
CHRONIC LEG ULCERS & 2 & 2.9 \\
SEVERE INFECTION/ ASCENDING SEPSIS & 2 & 2.9 \\
\hline
\end{tabular}

Table 3. Outcome of Amputation Surgeries In Male Patients

\begin{tabular}{|c|c|c|}
\hline OUTCOME & NO. OF PATIENTS & PERCENTAGE \\
\hline PRIMARY WOUND HEALING & 33 & $47.8 \%$ \\
\hline WOUND INFECTION & 30 & $43.5 \%$ \\
\hline WOUND DEHISCENCE-NEEDED $\quad 2^{\circ}$ & & \\
\hline SUTURING & 3 & $4.3 \%$ \\
\hline FLAP NECROSIS-NEEDED BONE & & \\
\hline SHORTENING/REFASHIONING & 3 & $4.3 \%$ \\
\hline $\begin{array}{l}\text { ASCENDING GANGRENE / INFETION- } \\
\text { NEEDED PROXIMAL RE-AMPUTAION- }\end{array}$ & & \\
\hline BKA to AKA & 3 & $4.3 \%$ \\
\hline POST-OP. DEPRESSION & 2 & $3.1 \%$ \\
\hline DEATH & 4 & $6.3 \%$ \\
\hline
\end{tabular}

\section{Discussion}

Major extremity amputations represent a serious disability, this being compounded in the developing world by the difficulty in obtaining prosthesis and the consequences of loss of earning abilities particularly if the patient is the only wage earner for a large extended family. ${ }^{1}$

The male sex takes more risk and is involved in more physical exertions, thus predisposing him to more injuries that may result in amputations ${ }^{.1,2}$.

Male predominance has thus been the norm in many previous studies on limb amputations. ${ }^{1,2,4,5,8,9,11 .}$ The finding in this study is also similar as $63(73.3 \%)$ of the 86 patients that had limb amputations in this centre during the study period were males. The high level of male involvement is of immense socioeconomic importance. The male being the major bread winner in most families, the whole family and probably the extended family is as result thrown into deprivation with far reaching effects on the economy and the society.

The average age of the patients in this study was $48.7 \pm 20.6$ years. This is similar to the mean ages of $47.49 \pm 13.20$ years reported by Jawaidet $\mathrm{al}^{1}$ and $47.6 \pm 20$ years reported by Dada and Awoyomi ${ }^{4}$ for both sexes. It is however lower than the mean of 54.4 years observed by Ofeali ${ }^{12}$ and $53.8 \pm 18.3$ years recorded by Odatuwa-Omagbemi and Adiki ${ }^{2}$, but higher than the averages of $35 \pm 22$ years and 39.7 years reported by Olasinde et $\mathrm{al}^{7}$ and Hamzy et $\mathrm{al}^{8}$ respectively for both sexes.

The peak age groups for amputations in male patients in this study were the age groups of $15-24$ years $(20.6 \%)$ and $45-54$ years $(22.2 \%)$. These groups fall within the active and productive groups in any society. With the poor prosthetic and rehabilitative facilities in Nigeria where there is also little or no social support system, the negative impact of amputations in this age group can only be imagined. All hands must thus be on deck to prevent amputations in the first place and improve on rehabilitative and prosthetic facilities for those who must have amputation or are already amputees. Also, our social support system needs to be improved upon.

The commonest indication for amputation in male patients in this study was diabetic foot disease which accounted for about $38 \%$ of cases. The importance of diabetic mellitus as the most important indication for amputation has also been similarly reported in several recent studies. ${ }^{1,2,4,8}$. The relative importance of diabetes however varies from study to study. Relatively higher percentages of $54.7 \%$ and $45 \%$ have been reported by Jaiwadet $\mathrm{al}^{1}$ and Dada and Awoyomi ${ }^{4}$ respectively in their studies for both sexes. In contrast, Thanni and Tade ${ }^{13}$ in a review of indications for amputations in Nigeria reported trauma as the commonest indication while Umaruet $\mathrm{al}^{11}$ recorded gangrene resulting from traditional bone setters activities as the commonest indication for limb amputations in their study.

About $46 \%$ (32 patients) of amputations in this study were at below knee level making it the most frequent levelof amputation done in males in our centre. This agrees with findings from several previous studies on both sexes. ${ }^{2,4,5,8}$. However a contrasting finding have been reported by Akiode et $\mathrm{al}^{9}$ and Umaru et al ${ }^{11}$. Both groups reported above knee amputation as the commonest level of amputation in their studies. Of particular note is that in the latter two studies trauma and lower limb gangrene resulting from activities of traditional bone setters were the commonest indications for amputation while in the former group, diabetic foot disease and other peripherial vascular problems were the commonest indications for amputations. It would appear that trauma and 
gangrene resulting from traditional bone setters' treatment of limb injuries cause relatively more extensive tissue damage and thus require more radical surgeries in order to save the patients' lives compared with other indications for amputation.

More than half $(52.2 \%)$ of the patients in this study developed one post-operative wound complications or the other which ranged from wound infection, flap necrosis to ascending gangrene requiring more proximal re-amputation in some cases. Wound infection was the commonest post-operative complication occurring in $43.5 \%$ of wounds. This wound infection rate is higher than that reported by some previous authors $1,2,4.7,10,12$. which ranged from $20 \%$ to $36.4 \%$, but much lower than $68.3 \%$ and $72.5 \%$ observed by Olasinde et al ${ }^{7}$ and Akiode et $\mathrm{al}^{9}$ respectively. It is important to note that post-operative wound infection rate after amputation surgeries is often increased by pre-operative conditions of the limb in addition to other co-morbidities the patient may have. Diabetic foot gangrene with ascending sepsis often markedly increase the risk of postoperative wound infection as also gangrene with sepsis resulting from traditional bone setters' treatment of limb injuries. Some of these conditions may warrant a two stage procedure of initial open amputation and later wound revision and closure when soft tissue conditions improve.

Another very important indicator of peri-operative morbidity, is the length of patients' hospital stay which is often largely dictated by post-operative wound complications such as ; infections, wound dehiscence, flap necrosis; the need for multiple surgeries and the presence and level of control of other comorbid surgical and medical conditions. The average length of hospital stay of male amputees in this study was $37.14+25.7$ days. This is higher than 17.3 days and 26.6 days reported by Jawaidet al $^{1}$ in Pakistan and Dada and Awoyomi ${ }^{4}$ in Lagos, Nigeria respectively.

Four of the patients died in the post-operative period in this study giving a post-operative mortality of $6.3 \%$. This is similar to a $6.5 \%$ reported by Odatuwa-Omagbemi and Adiki ${ }^{2}$ and $7.2 \%$ reported by Akiodeet $\mathrm{al}^{9}$ respectively. In contrast, Ofeali ${ }^{12}$ recorded a higher figure of $15.2 \%$ while Dada and Awoyomi ${ }^{4}$ reported $16.2 \%$ post-operative mortalities. Better peri-operative care and control of co-morbid conditions might have accounted for the relatively low post-operative mortality in this study.

\section{Conclusion}

The predominance of male sex involvement in amputations has again been brought to limelight in this study with many of them still within the active age group fending for their families. This portends danger for a resource scarce society like Nigeria with no social support system. There is thus need to prevent/control the conditions such as diabetic foot ulcer/gangrene and trauma resulting mainly from road traffic crashes in the first instance and to establish well equipped and functional rehabilitative and prosthetic centres for amputees in our hospitals. Government subsidy on prosthesis will go a long way in making the amputees more functional and independent instead of becoming beggars. The need for wide spread education of diabetics on foot care and glycaemic control including regular blood sugar screening for the aging population cannot be overemphasised. So also is the need for public enlightenment on road safety precautions and control of activities of traditional bone setters.

\section{References}

[1]. Jawaid M, Ali I, Kaimkanni GM. Current Indications for Lower Limb Amputations at Civil Hospital, Karachi, Pakistan. Journal of Surgery. 2008; 24(4): 228-231.

[2]. Odatuwa-OmagbemiDO, Adiki OT. Extremity Amputations in Warri, South-South Nigeria. J West AfrColl Surg. $2012 ; 2(1)$ : 14-24.

[3]. Adegbehingbe OO, Akinyoola AL, Oginni LM. Predictive Factors for Primary Amputation in Trauma Patients in a Nigerian Teaching Hospital. East Afr Med J. 2006; 83(10): 239-244.

[4]. Dada AA, AwoyomiBO. Is The Trend Of Amputation in Nigeria changing? A Review of 51 Consecutive Cases Seen At the Federal Medical Centre, EbuteMetta, Lagos, Nigeria. Niger J Med. 2010; 51(4): 167-169.

[5]. Abbas AD, Musa AM. Changing Pattern of Extremity Amputations in University Of Maiduguri Teaching Hospital, Nigeria. Niger J Med. 2007; 16(4): 330-333.

[6]. Ekere AU. The Scope of Extremity Amputations in A Private Hospital In South-South Region of Nigeria. Niger J Med. 2003. OctDec.; 14(4): 24-27.

[7]. Olasinde AA, Oginni LM, Bankole JO, Adegbehingbe OO, Oluwadiya KS. Indications for Amputations In Ile-Ife, Nigeria. Niger J Med. 2002. Jul-Sep. 11(3): 118-121.

[8]. Hazmy W, Muhamad M, Ashikin N, Jamilah S, Yee LE, Shong HK. Major Limb Amputations InSerebian Hospital: A Review Of 204 Cases From 1997-1999. Med J Malaysia. 2001; 56(suppl c): 3-7.

[9]. Akiode A, Shonubi AMO, Musa A, Sule G. Major Limb Amputations: An Audit of Indications In A Sub-urban Surgical Practice. J Nat Med Association. 2005; 97: 74-78.

[10]. Obalum DC, Okeke GC. Lower Limb Amputations at a Nigerian Private Hospital. West Afr J med. 2009 ; $28(1)$ : $24-27$.

[11]. Umaru RH, Gali BM, Ali N. The Role of Inappropriate Traditional SplintageIn Limb Amputation In Maiduguri, Nigeria. Annals of African Medicine. 2004; 3(3): 138-140.

[12]. Ofiaeli RO. Indications, Levels and Outcome of Lower Extremity Amputations InNnewi, Nigeria. JOMIP. $2001 ; 2(5): 18-21$.

[13]. Thanni LOA, Tade AO. Extremity Amputations In Nigerian - A Review of Indications And mortality. Surgeon. 2007; 5(4): 213217. 